\title{
DISCUSSIE
}

\section{Naar een kritische en relevante rechtstheorie}

\author{
Pauline Westerman
}

Toen ik als pas afgestudeerd wetenschapsfilosoof een baan zocht, maakte mijn vriend me attent op een advertentie in de plaatselijke universiteitskrant waarin ze iemand vroegen die het natuurrecht wilde bestuderen. 'Kijk', zei hij. 'Is dit niet iets waar jij nu eigenlijk mee bezig bent?' Inderdaad had ik me daar wat in verdiept, geïntrigeerd als ik was door de overeenkomsten en verschillen met wetenschappelijke natuurwetten. Tot onze verbazing lazen we dat deze positie vrijgegeven was op de faculteit rechtsgeleerdheid bij de sectie rechtsfilosofie. Rechtsfilosofie? Ik had er nog nóóit van gehoord, in al die negen jaren dat ik filosofie had gestudeerd. Ik besloot te solliciteren en ik kwam er nooit meer weg.

Ik heb geen reden te veronderstellen dat het een huidige afgestudeerd filosoof anders vergaat. Nog steeds bereiken mij mails als: 'ik ben vierdejaars filosofiestudent en wil mijn masterscriptie gaan schrijven over recht en rechtvaardigheid. Ik zag toevallig op de site dat u zich daarmee bezighoudt. Bij filosofie kan niemand me begeleiden, maar zou u me misschien hier meer over willen vertellen?' Een onredelijk gevoel van ergernis bekruipt me dan. Weer zo'n arrogante filosoof die me vraagt even in een mail een heel vakgebied uit te leggen! U voelt het al: ik ben in de loop der tijd dusdanig gejuridiseerd geraakt dat ik de rechtsfilosofie als een echt vakgebied ben gaan beschouwen. Als mijn vakgebied. Maar ook ik ben er nadien nooit in geslaagd filosofen uit te leggen dat recht minstens zo belangrijk is als taal of wetenschap en de rechtsfilosofie dus meer is dan slechts een onbelangrijk onderdeel van de sociale filosofie. Sterker, ik ben het contact met medefilosofen goeddeels verloren. Een niet onbelangrijke reden daarvoor is dat ik blij was het heetgebakerde strijdtoneel van de filosofie te verruilen voor het meestal bedachtzame en plezierige juristengezelschap.

Maar er is ongetwijfeld ook een meer structurele oorzaak aan te wijzen voor mijn geleidelijke toenadering tot de wereld van het recht. Mij bleek dat ik, wilde ik als rechtsfilosoof productief zijn, vooral baat had bij een venster op het recht en bij een dagelijks contact met juristen. Op zich is dat gek, want voor de wetenschapsfilosofie geldt dat in veel mindere mate. Ik had me als wetenschapsfilosoof geen moment gehinderd gevoeld door het feit dat ik zelf geen wetenschapper was. Je kunt je leven lang theoretiseren over de vooruitgang in de wetenschap en hulphypothesen opstellen bij de rationele reconstructie van die vooruitgang zonder ook maar het minste begrip te hebben van golven en deeltjes. Bij de rechtsfilosofie is dat veel moeilijker. Zij lijkt een zekere autonomie te ontberen en is voor haar voortbestaan afhankelijk van zowel rechtspraktijk als rechtswetenschap. In zekere zin reproduceert de rechtsfilosofie daarmee de stand van zaken in de 
rechtswetenschap zelf, die op haar beurt ook weer afhankelijk is van de rechtspraktijk en zich ook voedt door voortdurend contact met die praktijk.

$\mathrm{Nu}$ zijn dit grote woorden die wellicht meer suggereren dan kan worden beargumenteerd. Want het is één ding om te beweren dat scheiding van rechtsfilosofie en recht onwenselijk is maar een heel ander ding om te zeggen dat een dergelijke scheiding onmogelijk is. Om deze laatste bewering kracht bij te zetten moeten we goed voor ogen houden wie nu eigenlijk wie nodig heeft. Heeft de filosofie het recht nodig of heeft het recht nood aan filosofische reflectie?

Ik denk dat vooral het laatste het geval is. Juristen hebben meestal het gevoel dat filosofen iets kunnen en weten dat ze niet op eigen kracht kunnen ontdekken. Toegegeven, deze behoefte aan rechtsfilosofische verdieping ziet men niet altijd terug in de budgettaire mogelijkheden die de rechtsfilosofieafdelingen krijgen geboden, noch in de personele opbouw van de faculteit of de plek van het vak rechtsfilosofie in het curriculum, maar op zich zegt dat natuurlijk niet veel. Men wil het voor een koopje hebben, maar niettemin wil men het wel hebben! Als rechtsfilosoof word je daarom toch met een zeker respect bejegend. U begrijpt nu ten volle waarom ik het juristengezelschap prefereer boven dat van de filosofenfamilie, waar men nooit meer zal kunnen worden dan het enigszins sneue achternichtje met een onduidelijke negotie.

Juist omdat juristen filosofie nodig hebben, is de enige bestaansreden van de rechtsfilosofie als aparte discipline dat zij zich op die noden oriënteert. En dat kan natuurlijk weer alleen als de filosoof haar oor te luisteren legt bij juridisch geschoolde collega's. Doet zij dit niet, dan kan ze zich tooien met namen als sociale filosofie of politieke filosofie of ethiek of god weet wat, maar dan is het geen rechtsfilosofie meer.

Dat lijkt een geweldig open deur en dat is het ook, maar er liggen wel enkele misverstanden op de loer die onmiddellijk en met kracht moeten worden bestreden. Want voorzien in de behoefte van juristen betekent niet dat men voorziet in behoeften zoals juristen die zelf voelen en verwoorden!

Een voorbeeld van zo'n door juristen diepgevoelde behoefte is de behoefte aan grondslagen. Ik was nog maar net op de rechtenfaculteit aangesteld toen de toenmalige hoogleraar burgerlijk recht op me af kwam lopen en zei: 'Zo, kijk eens aan, een nieuwe rechtsfilosoof. En jij gaat ons dus helpen de grondslagen van het recht te vinden.' Gepokt en gemazeld als ik was in postmodernistisch anti-foundationalism dacht ik eerst dat het een geintje was, maar dat was het niet. Ik zei toen heel dom, dat ik niet geloofde in grondslagen en het is maar goed dat de man daarna snel met pensioen ging want het is niet meer goed gekomen tussen ons. Nog verbijsterender dan de inhoud van het verzoek was het feit dát het verzoek tot mij gericht was. Bij mijn weten komt het zelden voor dat een natuurwetenschapper een filosoof om hulp vraagt, niet om de vooruitgang te verklaren, niet om de fundamenten van de natuurwetenschap te onthullen en ook niet om hem te vertellen 
welke theorie de voorkeur verdient. Dat weet zo'n natuurwetenschapper immers zelf het beste. En mocht zo'n wetenschapper ooit al iets gewaarworden van wetenschapsfilosofische theorieën, dan volgt in de regel hoongelach en ongeloof.

De verleiding is dan ook groot om alle postmodernistische bezwaren opzij te zetten en zich op die zo gewenste grondslagen te bezinnen. Toch ligt hier een gevaar op de loer. Wie zich voordoet als grondslagenbouwer, graaft uiteindelijk zijn eigen graf want die taak kan helemaal niet worden verricht door de filosoof. Hoe zou dat ook kunnen? Het recht is voor een groot deel ontstaan uit collectieve en eeuwenlange inspanningen van nijvere en ingenieuze juristen die zich voor tal van concrete problemen en conflicten zagen geplaatst, waarvoor ze oplossingen hebben verzonnen. Die oplossingen moesten op hun beurt wel weer gemotiveerd worden en het streven is dan om een uitgangspunt te kiezen dat voldoende abstract is om meerdere oplossingen tegelijk te rechtvaardigen. Zie daar de geboorte van het beginsel. Een beginsel als 'de vervuiler betaalt' kan als argument dienen voor meerdere milieuregels tegelijkertijd. ${ }^{1}$

Het verlangen naar grondslagen moet denk ik begrepen worden als de veronderstelling dat nóg abstractere beginselen nóg meer regels kan rechtvaardigen tot, jawel, het ganse rechtsgebouw door slechts enkele pijlers gestut wordt. Juristen hopen dat dergelijke grondslagen, een soort superbeginselen in feite, precies datgene doen wat de gewone beginselen ook doen. Die taak is tweeërlei. Beginselen verlenen coherentie in het recht waar zij als knooppunten dienen voor meerdere verschillende regels en tegelijkertijd als normatieve rechtvaardiging voor die regels. De gedachte is nu dat grondslagen hetzelfde doen, maar dan bij voorkeur voor het hele rechtssysteem. Door coherentie te verlenen aan rechtsbeginselen zouden die grondslagen hele rechtsgebieden met elkaar kunnen verbinden tot een eenheid. En tegelijk zouden ze dan de ultieme normatieve rechtvaardiging kunnen bieden voor dat rechtssysteem. Althans dat hoopt men. Maar het is precies op dit punt dat de jurist dan plots lijkt te gaan twijfelen aan de eigen capaciteiten. Men meent niet diep genoeg te kunnen graven om zelf deze nog abstractere funderingen aan te leggen en dat alleen filosofen in staat zijn diepere lagen aan te boren.

Maar natuurlijk hebben filosofen helemaal niet zo'n diepteboor tot hun beschikking. Integendeel, van alle disciplines zijn filosofen het minst geëquipeerd om funderingen aan te leggen. Het is dan ook van groot belang om de hooggespannen verwachtingen van de jurist direct de bodem in te slaan en erop te wijzen dat de filosoof een essentieel andere taak heeft. Waar de jurist conflicten wil oplossen, compromissen wil vinden en coherentie en samenhang zoekt, daar zoekt de filosoof naar spanningen en tegenstrijdigheden. Als filosofen zich al bezighouden met fundamenten dan zullen ze, tenminste als het goede filosofen zijn, onmiddellijk signaleren dat een en dezelfde pijler - aangebracht in de rechtspraak en geci-

1 Een mooie illustratie hiervan voor het ondernemingsrecht is nog steeds L. Timmerman, Grondslagen van Ondernemingsrecht, 2009, https://www.recht.nl/vakliteratuur/ondernemingsrecht/ aflevering/10854/ondernemingsrecht/2009/1/\#a177753. 
teerd in de rechtswetenschap - totaal verschillend geïnterpreteerd kan worden en zullen zij daarover gaan harrewarren. Of ze zien dat er in de loop van de geschiedenis verschillende pijlers zijn aangebracht onder het juridische bouwwerk en zullen erop wijzen dat die niet met elkaar verzoend kunnen worden. Juristen willen dat niet graag horen; ze hebben in de regel de neiging conflicten te verzachten en op te lossen. Een heel mooi voorbeeld is de in het strafrecht herhaalde mantra dat 'vergelding de grondslag is maar preventie het doel'. Ook een term als 'democratische rechtstaat' is ervoor gemaakt om eventuele spanningen tussen rechtstatelijkheid en democratie onder het tapijt te vegen. De meest verschillende ideeën worden allemaal aangeduid met het alles verhullende 'gelijkheidsbeginsel'. Het summum van deze neiging om de kool en de geit te sparen is wel de contemporaine mode-term T-shaped lawyer, een term die suggereert dat er geen keus gemaakt hoeft te worden tussen specialisering en interdisciplinariteit. Voor een T heb je immers een horizontaal en een verticaal lijntje nodig: we hoeven niet te kiezen.

Dit bedoel ik niet badinerend. Men mag dergelijke compromissen zien als bloedeloze dooddoeners, maar de taak van juristen ligt nu eenmaal niet in de eerste plaats in het entameren van levendige discussies. Hun streven naar coherentie en eenheid is van belang voor ordelijk en enigszins voorspelbaar samenleven. Voor de filosoof zijn dergelijke compromissen en halfslachtige middenwegen echter doodzonden. Als filosofen zich al met grondslagen moeten bezighouden, dan moeten die geëxpliciteerd en vooral geproblematiseerd worden. Verzwegen veronderstellingen moeten aan het licht worden gebracht, gemaakte keuzes moeten worden benoemd, compromissen vermeden en spanningen moeten juist worden bediscussieerd. En als de filosoof dat allemaal heeft gedaan, dan mag de jurist weer proberen de zaak aan elkaar te lijmen maar nu wijs geworden door het inzicht dat dat niet makkelijk is en dat er meer bij komt kijken dan woordjes achter elkaar zetten.

Zoals ik zonet al opmerkte, kan het verlangen naar grondslagen niet alleen begrepen worden uit het streven naar coherentie. De tweede reden waarom de jurist naar grondslagen zoekt, is het verlangen naar normatief houvast. Ook hier koestert men verwachtingen van de filosoof. Hoe prachtig zou het niet zijn als de filosoof zou aangeven wat billijk en onbillijk is, wat rechtvaardig en onrechtvaardig. Ik zie het elk jaar weer aan mijn studenten. Als ze al eens rechtop gaan zitten - en geloof me, sommigen gáán rechtop zitten - dan is het bij de altijd maar weer spannende verhalen over Radbruch die de rechtszekerheid opzij wil zetten voor de gerechtigheid en die muurschutters van de DDR die wel volgens de wet hebben gehandeld door op eigen burgers te schieten maar niettemin vervolgd moeten worden. Wat is rechtvaardigheid? Men spitst onmiddellijk de oren.

Ook hier komt het erop aan dit soort prille belangstelling onmiddellijk te smoren. Want kijk om je heen, geen enkel antwoord kan dienen als het laatste woord, geen enkele theorie is onomstreden, je kan altijd verder graven en men eindigt in drijfzand. Dat moeten we ze leren, deze jongens en meisjes, die bij de colleges staatsrecht in slaap zijn gewiegd toen ze leerden dat democratie en rechtstaat in elkaars verlengde liggen en om het even door contract dan wel God zijn bekrachtigd in 
een wereld waarin het wenselijke en het gewenste vloeibaar in elkaar overlopen. We moeten hun leren dat ook filosofen geen normatief uitsluitsel kunnen geven. Sterker nog: dat filosofen hier geen antwoord op mogen geven. Wat goed of slecht recht is, kan alleen door de burgers zelf worden bepaald; de filosoof kan alleen koning zijn in een totalitaire maatschappij.

Uit deze opmerkingen zou de jurist kunnen concluderen dat het respect en het ontzag dat de filosoof gewoonlijk geniet op een rechtenfaculteit niet verdiend zouden zijn. Het zijn kibbelaars, geen gelegenheid onbenut latend om verwarring te scheppen, grondvesten op drijfzand te laten berusten in een nooit eindigend steekspel tussen voors en tegens waarbij spitsvondigheden de simpele juristenziel van streek maken. Deze conclusie, dames en heren, zou onterecht zijn. Want natuurlijk hebben rechtsfilosofen de jurist veel te bieden. Oneindig veel meer zelfs dan die saaie in beton gegoten fundamenten.

Ik herinner me dat mijn moeder me ooit vroeg wat ik die wetgevingsjuristen in Den Haag toch in vredesnaam ging vertellen. 'Nou', zei ik, 'ik vertel hun bijvoorbeeld wat een regel is'. Ze kon daar niet over uit. 'Moet jij ze dat vertellen?! Die lui maken toch regels, dan zullen ze toch beter weten wat het zijn dan jij?' Ja, dat zou je denken. Maar het is niet zo. Geen wetgevingsjurist, of zij nu aspirant of ervaren is, weet wat de structuur is van een regel, noch wat het verschil is tussen een algemene en een abstracte regel. Hetzelfde geldt voor rechten, plichten en bevoegdheden. Men legt ze op, maar wat het voor dingen zijn en op welke verschillende manieren je erover kan praten en denken? Dat moet de rechtsfilosoof vertellen! De praktiserende jurist verklaart contracten of testamenten aan de lopende band als geldig of nietig, maar wat dat betekent - en hoe het mogelijk is dat men een proces voor niet-bestaand verklaart, terwijl er toch tientallen mensen bij aanwezig zijn geweest - daarvan weet de jurist weinig tot niets.

De voorbeelden die ik noem, hebben niets te maken met grondslagen; het zijn eenvoudige, onthutsend eenvoudige explicaties van juridische technieken. Rechtsfilosofie is ook hier vooral explicitering. Vertellen wat juristen eigenlijk doen als ze een regel maken of toepassen, inzichtelijk maken wat je kan doen met een juridisch begrip en dat dat iets anders is dan een empirisch begrip, vertellen dat er spanningen zijn tussen legitimiteit en draagvlak, erop wijzen dat je een regel kan zien als argument en ook als instrument maar dat je dan wel verschillende eisen aan een regel stelt ... noem maar op. De recente rechtsfilosofische aandacht voor de relatie tussen dogmatische en empirische methoden is in die zin dan ook een wezenlijke en verhelderende bijdrage aan het methodendebat dat in de rechtswetenschap zelf gevoerd wordt. Ook hier komt het erop aan de gebruikelijke gehanteerde perspectieven en veronderstellingen te expliciteren. Of die bekritiseerd of toegejuicht worden, lijkt me dan van secundair belang. Het gaat erom dat we eerst duidelijk hebben waarover we het hebben. Dat lijkt een bescheiden taak, maar kan een leven vullen. 
Of niet? Met die vraag worstel ik momenteel. Van de honderd jaar dat deze vereniging bestaat, heb ik er zelf dertig meegemaakt; bijna een derde! In die dertig jaar was er veel werk aan de winkel en het grootste deel daarvan heb ik me beziggehouden met het bovengenoemde expliciteren, het signaleren van verzwegen assumpties en het opsporen van onbenoemde spanningen en tegenstrijdigheden. Ik heb dat met veel plezier gedaan en $\mathrm{ik}$ heb dat alleen kunnen doen doordat juristen steeds geduldig aan mij uitlegden wat ze dachten dat ze deden en wat zij dachten dat het probleem was. Zonder die informatie had ik de misverstanden en de tegenstrijdigheden niet kunnen opsporen en het is om die reden dat ik altijd bepleit dat men in nauw contact moet staan met de juristenwereld.

Maar na dertig jaar lang te hebben uitgelegd wat het verschil is tussen primaire en secundaire regels, en dat het typerend voor recht is dat zij beide soorten regels bevatten, denk ik nog vaak aan de opmerking van dat ene pientere meisje dat haar vinger opstak en zei: wij hebben thuis ook een secundaire rule of recognition: mama's wil is wet! Ze had natuurlijk gelijk. In allerlei contexten heeft men metaregels die bevoegdheden verlenen en plichten opleggen. In allerlei contexten zijn er regels die bepalen welke regels en bevelen er wel of niet toe doen. Waarom zouden we denken dat alleen traditionele nationale rechtssystemen metaregels hebben? En waarom denkt men dat de status van internationaal recht afhankelijk is van de mogelijkheid om daarin secundaire regels te identificeren? ${ }^{2}$

Het is op dit punt dat de rechtsfilosoof gehinderd wordt door een al te nauwe band met de wereld van de praktiserende jurist. Want voor de jurist is het belangrijk om te kunnen bepalen wat rechtens geldig is en hoe hij dat geldend recht kan herkennen. Maar voor de filosoof is dat van veel minder groot belang. De filosoof wil uiteraard wel begrijpen wat geldigheid betekent binnen de wereld van het recht en wat er eigenlijk gebeurt als mensen aan contracten juridische geldigheid toeschrijven. Ook is het prachtig als deze inzichten vervolgens worden gedeeld met juristen. Maar de filosoof hoeft zelf geen juridische beslissingen te nemen. Daarom is er geen directe praktische noodzaak om te bepalen wat rechtens geldig is en wat niet, wat hard law is en wat soft law of wat het verschil is tussen een juridische en een morele verplichting.

Ik denk dat de eindeloze discussies over de grenzen tussen moraal en recht dan ook vooral zijn ingegeven door een te gretige vereenzelviging met de behoeften van jurist. Uiteraard; diegenen die zich gesteld zien voor de taak om juridische beslissingen te nemen inzake concrete 'moeilijke gevallen' willen terecht weten in hoeverre de rechtszekerheid geschaad wordt bij een beroep op redelijkheid en billijkheid. Ik zeg niet dat dergelijke discussies over de grenzen tussen moraal en recht filosofisch oninteressant zijn, maar het wordt toch wat penibel als daarmee de hele rechtsfilosofie wordt versmald tot dergelijke grensbepalingen. Ik denk

2 Hart zelf meende niet dat secundaire regels een noodzakelijke voorwaarde was, maar de discussie wordt wel vaak langs deze lijnen gevoerd. Zie voor een kritische bespreking Mario Prost, The Concept of Unity in Public International Law, OUP, 2012. 
echter dat, mede door de allesoverheersende Hart-Dworkin-debatten, deze versmalling daadwerkelijk heeft plaatsgevonden en dat betreur ik.

Ten eerste omdat een rechtsfilosofie die zich met name bezighoudt met jurisprudentie vooral het hulpje wordt van de rechtspraak. Tal van boeiende wetgevingsvraagstukken blijven dan onderbelicht, terwijl juist daar allerlei keuzes worden gemaakt waarvan men zich vaak niet bewust is. Economen, beleidswetenschappers en bestuurskundigen bezetten nu dit veld dat leeggelaten is door rechtsfilosofen en dat is jammer want die lieden zijn meestal weinig geneigd om keuzes te expliciteren en te problematiseren.

Maar belangrijker dan dat is toch dat deze versmalling een kritische filosofie van het recht, ik zou bijna zeggen een 'autonome' filosofie van het recht, in de weg staat. Wat een wereld aan interessante vraagstukken zou er wel niet ontsloten kunnen worden als we bevrijd zouden kunnen worden van de taak voortdurend te identificeren wat recht is, als we niet langer het recht zouden hoeven af te bakenen van moraal, politiek en andere sociale regels, als we niet langer ons hoeven bezig te houden met het trekken van krijtlijnen en niet te vergeten met het uitvegen van andermans krijtlijnen.

We zouden ons bijvoorbeeld kunnen bezighouden met de vraag onder welke voorwaarden een normatief systeem - dat wil zeggen een systeem waarin rechten en plichten worden opgelegd - ontstaat en onder welke voorwaarden zo'n normatief systeem werkelijk verschil maakt en 'ertoe doet'. In dit verband moet ik vaak denken aan die Indiase inspecteur, door mij regelmatig ten tonele gevoerd, die met de nieuwe Indiase arbowetgeving op zak de werkgevers uitperst onder bedreiging dat hij hun anders een boete oplegt en zo zijn eigen zakken vult. ${ }^{3}$ Hoe is het toch mogelijk dat de arbeidsinspectie dat bij ons niet doet en de meeste ambtenaren hun baan niet zien als een bron van persoonlijk gewin? Hoe is het mogelijk dat er in goed functionerende rechtssystemen regels worden opgesteld door personen of organen die door diezelfde regels in hun vrijheid en macht worden beknot? Of nog breder: onder welke voorwaarden heeft überhaupt de gedachte kunnen opkomen om regels, beloften of afspraken te ontwerpen die kunnen dienen als belangrijker redenen voor gedrag dan gewone eersteorderedenen, zoals individueel dan wel collectief eigenbelang?

Begrijp me goed: ik zoek op mijn oude dag niet toch nog naar normatieve uitgangspunten. Ik ga niet opeens in grondslagen geloven zoals mensen die op de rand van de dood zich opeens tot god bekeren. Ik streef echt niet naar de mogelijkheid om filosofisch gefundeerd 'foei' te roepen tegen die inspecteur. Ik wil alleen begrijpen onder welke voorwaarden er een effectief normatief stelsel kan ontstaan, hoe dergelijke vormen van zelfbinding mogelijk zijn die indruisen tegen het directe eigenbelang.

$* * *$

3 Voor deze en andere voorbeelden Jan Breman, The Poverty Regime in Village India: Half a Century of Work and Life at the Bottom of the Rural Economy in South Gujarat, Oxford UP, 2007. 
$\mathrm{Nu}$ kan men deze vragen naar de mogelijkheidsvoorwaarden op twee manieren begrijpen. Men kan ze begrijpen als varianten op de welbekende kantiaanse vraag naar de transcendentale mogelijkheidsvoorwaarden en men kan ze begrijpen als vragen naar historische of sociologische oorzaken. Een bekend voorbeeld van zo'n transcendentale vraag is: hoe kunnen we inzichtelijk maken wat moraliteit is? Het kantiaanse antwoord is dan dat moraliteit alleen denkbaar is vanuit de aanname dat de mens vrij is om voor het goede dan wel het kwade te kiezen. Vrijheid is daarmee een transcendentale voorwaarde voor moraliteit: het is logisch onmogelijk dat onvrijheid en moraliteit samengaan. We kunnen recht ook zo benaderen en op zoek gaan naar de noodzakelijke, niet-contingente voorwaarden voor recht. Men beperkt zich dan tot een conceptueel analyseniveau en onderzoekt welke concepten noodzakelijkerwijs moeten worden voorondersteld om een ander concept betekenis toe te kennen. Eeuwenlang gold de menselijke rationaliteit als zo'n noodzakelijke voorwaarde voor recht. Een recenter voorbeeld is Kelsens Grundnorm, een norm waarvan de geldigheid moet worden voorondersteld om betekenisvol te kunnen spreken over geldigheid. Veel rechtsfilosofisch onderzoek is van deze conceptuele aard en hoewel Hart aankondigt dat hij een descriptieve sociologische analyse gaat geven van recht, heet zijn boek toch The Concept of Law en niet The Phenomenon of Law.

Het geweldige voordeel van een conceptuele benadering is de helderheid die ze kan bieden. Het behoedt ons ervoor om willekeurig welk fenomeen als 'recht' te bestempelen en het maakt ons gevoelig voor de omstandigheid dat datgene wat men identificeert als een juridisch fenomeen sterk afhankelijk is van het concept van recht dat men hanteert; een concept dat het resultaat is van een keuze om bepaalde eigenschappen wel en andere niet in de beschouwing te betrekken. Men kan geen sociologische beschrijving geven zonder conceptuele analyse en daarom is Harts titel juist gekozen.

Maar we moeten vervolgens niet op dat conceptuele niveau blijven steken. De verschillende betekenissen van de notie van een subjectief recht die Hohfeld heeft ontrafeld, zijn bijzonder waardevol. Maar als je wilt weten onder welke voorwaarden die rechten succesvol kunnen worden afgedwongen, in welke betekenis dan ook, dan kun je niet met Hohfeld volstaan. Nu kan men hier tegenin brengen dat dat ook geen filosofische vraag is, maar een sociaalwetenschappelijke die het bereik van de filosofie nu eenmaal te buiten gaat. Maar mijn vraag is nu juist: moeten we ons bij deze taakverdeling neerleggen? Moeten we filosofie beperken tot conceptuele analyse en al het andere tot buiten onze competentie verklaren? Waarom zouden we dat doen? Verbannen we daarmee niet een groot deel van de wereld naar buiten ons gezichtsveld? ${ }^{4}$

4 Opmerkelijk genoeg heeft de wetenschapsfilosofie wel een stap naar een meer empirische benadering gemaakt en wel al sinds Woolgar and Latour het laboratorium ingingen om de wetenschap daadwerkelijk in de praktijk te kunnen bestuderen. Bruno Latour and Steve Woolgar, Laboratory Life: The Construction of Scientific Facts, Princeton University Press 1979. 
Een groot nadeel van conceptuele analyse pur sang is dat zij zich beperkt tot een analyse van concepten die in ons rechtssysteem nu eenmaal van belang zijn. In 'ons' recht speelt geldigheid een belangrijke rol en daarom moeten we zoiets als een Grundnorm vooronderstellen. Maar misschien is dat bij andere rechtssystemen helemaal niet zo. Misschien draait het daarin helemaal niet om geldigheid en hoeven we zo'n Grundnorm ook niet te veronderstellen. Kant kan wel een noodzakelijk verband leggen tussen recht en de mogelijkheid om de vrijheid van de een met die van de ander te verzoenen, maar dat verband tussen recht en vrijheid hoeft niet universeel te zijn, alle gepraat over universele noodzakelijkheid ten spijt. Willen we vat krijgen op de voorwaarden waaronder normatieve systemen verschil uitmaken voor het handelen, om dat voorbeeld maar weer te noemen, dan moeten we verschillende systemen gaan vergelijken en proberen een analyseniveau te vinden dat meer omvat dan de criteria en concepten die constitutief zijn voor ons eigen systeem. ${ }^{5}$

Dat kan alleen door de mogelijkheidsvoorwaarden voor een effectief normatief systeem op de tweede manier op te vatten die ik zojuist onderscheidde, namelijk als historische of sociologische oorzaken. We moeten dan concreet op zoek gaan naar die sociale, economisch en culturele factoren die het mogelijk maken dat een normatief stelsel ontstaat dat voldoende gezaghebbende redenen geeft voor mensen om anders te handelen dan dat zij zouden hebben gedaan zonder die normen. Willen we meer begrijpen van de betrekkelijke irrelevantie van het Indiase arborecht, dan zou het toch prettig zijn iets te weten over hoe dat officiële recht wordt gepercipieerd. Hoe lopen de scheidslijnen tussen publiek en privaat daar? Ziet men wel een conflict tussen publieke arboregels en de regel dat men goed zorgt voor de eigen familie? Of heeft men misschien zelf juist het gevoel dat recht na te leven? Filosofen weten dat helemaal niet. We filosoferen tot we een ons wegen over de scheidslijn tussen het publieke en private domein, maar hoe dat in India zit? Geen idee. De talloze sociaalwetenschappelijke studies over corruptie, familiebanden et cetera worden door rechtsfilosofen nauwelijks gelezen. En we hoeven helemaal niet eens naar India te gaan. Voorafgaand aan de Franse revolutie waren er talloze pogingen om de praktijk aan banden te leggen dat ambten konden worden gekocht. Waarom was dat? Wanneer werden die te kopen ambten een probleem en waarom? Moeten we daar niet naar kijken als we de huidige situatie willen begrijpen?

Ik hoor het gemor terwijl ik dit schrijf omdat u meent dat de rechtsfilosofie om het even alle kanten wordt uitgestuurd alleen maar vanwege mijn obsessie met die Indiase inspecteur. Maar de vraag is deze: hebben we nu echt de illusie dat we begrijpen wat recht is als we al deze dingen weigeren te onderzoeken? Hoe kunnen we ons als rechtsfilosoof verkopen als we geen enkel idee hebben hoe we het recht inzichtelijk en begrijpelijk kunnen maken, als we geen enkele betekenis kunnen verlenen aan het fenomeen recht, behalve dan door de wijsheden te herhalen

5 Han-Pile analyseert Foucaults werk als de poging zo'n analyseniveau te vinden waarbij transcendentale vragen op historische wijze worden benaderd. Zie Béatrice Han-Pile, Foucault, Normativity and critique as a practice of the self, Cont Philos Rev (2016) 49:85-101. 
over primaire en secundaire regels, het verschil tussen regel en beginselen, Grundnormen, soevereine staten of de vrijheid met een hoofdletter V?

Het wordt tijd om de blikrichting hier wat te verleggen. Heb ik zoëven nog bepleit dat we vooral onze oren te luisteren moeten leggen bij de juristen, dan is het nu tijd om een meer empirische oriëntatie te bepleiten. Want hoe waardevol conceptuele verheldering ook is, uiteindelijk wordt dit toch een steriele aangelegenheid als we zelf geen enkel idee meer hebben van wat recht in concreto is en doet en vooral wat het niet is en niet doet. In plaats van de Kelseniaanse vraag te stellen naar de geldigheid van de rechtsorde en te stellen dat de idee van geldigheid tot uitdrukking komt in het postulaat van de geldige Grundnorm, kunnen we ons bijvoorbeeld de vraag stellen of geldigheid nog steeds wel zo'n belangrijk criterium is. Wordt het criterium van geldigheid niet genuanceerd in de vele huidige soft-law-achtige arrangementen? In plaats van de zoveelste lezing van The Concept of Law zouden we ons kunnen afvragen hoe het komt dat er tegenwoordig boekseries bestaan met de titel 'Law and Regulation'. Wat betekent het dat men allerlei regels tegenwoordig labelt als vormen van 'regulering' in plaats van gewoon 'recht'? En hoe komt het dat er zoveel leerstoelen 'public governance' zijn ontstaan? Zijn termen als regulation en governance alleen maar modetermen of duiden ze ook echt nieuwe praktijken aan? En waaraan kan men deze nieuwe praktijken dan herkennen? Wat betekent dat voor de klassieke rechtstatelijke waarden? Hoe verhouden deze nieuwe praktijken zich tot de oude? Kunnen we de nieuwe praktijken tot begrip brengen? In hoeverre voldoen oude noties als machtenscheiding en legitimiteit nog om de nieuwe vormen en praktijken te beschrijven?

Of als men wil blijven bij de door mij opgeworpen vraag naar de mogelijkheidsvoorwaarden van recht überhaupt, is het dan strikt noodzakelijk om te blijven steken bij een kritiek op de bevelstheorie van Austin? Kunnen we niet gewoon ook eens kijken naar al die nieuwe rechtssystemen die in dit tijdgewricht ontstaan; niet alleen de Europese rechtsorde maar ook allerlei mini-rechtssysteempjes in het internationale recht die rond een bepaald verdrag ontstaan of rond een conflictoplossend orgaan? We hoeven niet terug te gaan naar de primitieve volken van de twintigste-eeuwse rechtsantropologie om te aanschouwen hoe dergelijke stelsels ontstaan, we hoeven de krant maar op te slaan om recht in statu nascendi te aanschouwen. Economen zoals Barry Weingast publiceren het ene na het andere artikel over dergelijke emerging legal orders. ${ }^{6}$ Waarom zien we zo bar weinig van deze inzichten terug in de rechtsfilosofische literatuur?

Door ons niet met dergelijke vragen bezig te houden, laten we de beschrijving van deze nieuwe ontwikkelingen over aan andere disciplines, niet alleen economen, maar ook sociologen, beleidswetenschappers, specialisten in internationale 
betrekkingen en regulation-specialisten. Wie dat een goed idee vindt, zou voor de aardigheid dergelijke studies eens moeten lezen. Want hoewel we daar veel nuttige informatie kunnen vinden die ons aan het denken kan zetten, conceptueel gezien is het daar vaak een woestenij. Geen enkele gevoeligheid voor verzwegen aannamen, gemaakte keuzen, impliciete waardeoordelen en alom conceptuele verwarring. Men 'meet' legitimiteit zonder enig idee te hebben van de verschillende betekenissen van die term, of men reduceert legitimiteit eenvoudigweg tot nalevingsbereidheid zonder die laatste term te problematiseren. Men vraagt zich geen moment af waarom 'compliance' en 'accountability' ineens belangrijk worden en men heeft er geen idee van dat termen als 'rechtstaat' of 'procedurele rechtvaardigheid' meer vragen oproepen dan verhelderen. Sterker: men vraagt zich niet eens af hoe het komt dat ze zelf ineens 'gedragswetenschappers' zijn gaan heten, in plaats van sociale wetenschappers. Waar bij de rechtsfilosofie ongeïnformeerde conceptuele analyse de boventoon voert, daar lijdt menig sociaalwetenschappelijke studie aan informatievergaring zonder enige reflectie op de theoretische uitgangspunten, als die al te ontwaren zijn.

Wat ligt er in zo'n situatie toch meer voor de hand dan de handen ineen te slaan? Waar de conceptuele steriliteit verholpen kan worden door nader empirisch onderzoek en waar empirisch onderzoek aan diepgang zou winnen door meer filosofische analyse, is het toch vreemd dat rechtssociologen en rechtsfilosofen dan nog steeds gescheiden wegen bewandelen. Rechtssociologie en rechtsantropologie maar ook rechtspsychologie hebben nog steeds hun eigen gremia en publicatiekanalen. Er mogen af en toe gezamenlijke bijeenkomsten worden georganiseerd, maar een werkelijk vruchtbaar samengaan? Nauwelijks. Veelzeggend is het bijvoorbeeld dat waar beide tijdschriften, zowel ons NJLP als Recht der Werkelijkheid met dezelfde problemen kampen zoals een teruglopend aantal spontaan aangeboden artikelen en waarvan de redacties in hetzelfde dilemma zitten (meer aansluiting bij internationaal publiek dan wel meer aansluiting bij de praktijk) er bij mijn weten geen discussie is geweest over de vraag of er misschien ook kan worden samengegaan. Waarom oriënteren we ons niet op een herstart van Recht en Kritiek? Het mag voor mij dan ook wel af en toe Law and Critique heten. Het pikante van deze gang van zaken is dat waar rechtsfilosofen wel een interdisciplinaire rechtswetenschap bepleiten waarin rechtsdogmatisch onderzoek wordt gecombineerd en aangevuld met empirische wetenschappen, zij dat zelf nauwelijks doen en de voeten graag drooghouden op conceptueel terrein, dat voornamelijk, zoals eerder gezegd, bestaat uit het trekken van krijtstrepen en het aanleggen van funderingen.

Wil de rechtsfilosofie kritisch en relevant blijven, dan zou ze zich moeten ontwikkelen tot rechtstheorie, waaronder ik dan versta een bundeling van filosofische, historische en sociaalwetenschappelijke inzichten in aard en functie van normatieve systemen. Relevant omdat de talloze nieuwe ontwikkelingen kunnen worden bestudeerd met behulp van empirisch materiaal, kritisch omdat de uitgangspunten van dat empirisch materiaal conceptueel tegen het licht gehouden worden. Relevant omdat zo'n rechtstheorie zich laat inspireren door de behoeften en 
de problemen van juristen, maar tegelijk kritisch daar zij niet slaafs het interne juristenperspectief volgt noch de agenda van beleidsmakers die wat gedragswetenschappelijke ondersteuning willen hebben.

Misschien wordt zo'n relevante en kritische rechtstheorie dan nog eens een volwaardige loot aan de filosofische boom, eentje waarvan men erkent dat haar onderwerp minstens zo belangrijk, zo niet belangrijker is dan kennis, taal of wetenschap, omdat het niets minder bestudeert dan al de voorwaarden waaronder samenlevingen normatieve structuur en vorm krijgen. Laat dit de agenda zijn voor de volgende honderd jaar. 